\title{
Improving the learning outcome of final projects for engineering students
}

\author{
Leon B. Larsen \\ University of Southern Denmark
}

Increased student uptake in the engineering programmes strains the time spent by researchers on supervision. At the same many students are challenged on their writing competences thus raising the demand for dedicated supervision. This combination threatens to lower the scientific quality of final projects and especially the written dissertations. In this work we first analyse the writing habits in a cohort of six students at different levels and from different programmes. Based on the analysis we identify two main problems: The students begin writing too late in the project and supervisors need more time to give feedback. After analysing challenges and resources we review solutions from literature and propose a three phase model for the distribution of activities over the project period. We present a supervision strategy consisting of group supervision, peer feedback and pretask lectures to mediate the identified problems. Finally we describe a teaching activity that we conducted for the aforementioned cohort aimed at mediating the identified problems and discuss the results.

\section{Introduction}

Producing written material at a high level is at the very core of higher education. It is practised and tested in large written assignments at all levels most prominently in the bachelor and master dissertations and in scientific papers. In engineering the written work is typically based on a practical project conducted by the students individually or in pairs and supervised by a researcher. Often such projects revolve around active research thus also benefiting the supervisor. Supervisors are usually chosen based on their area of expertise and thus it is not uncommon to supervise multiple homogeneous projects at the same time but in a mixture between bachelor, master and PhD projects.

Although modern didactic methods are applied in most courses these days, the methods applied in project supervision have not changed much and are quite ineffective. The bulk of supervision follows the teaching model (Dysthe et al., 2006) where the supervisor takes on the expert role and consisting of face-to-face meetings between one student or group and the supervisor. The content of such meetings is centred around the progress made since last meeting and what tasks to do next. Even if this is a well proven approach to get students through the system, it scales poorly with increased student intake and thus strains the time spent by researchers on supervision. A natural consequence is that management is forced to limit the time spent by imposing constraints on how much time a project can claim, how much feedback each student can expect or how many pages the final project can fill. Since writing skills are generally expected to be developed prior to university level and since the researcher is naturally more interested in the contents that is often prioritised over the written work.

There is a tendency to view final projects as a demonstration of the skills acquired by the student throughout the education programme. This leads to supervisors being reluctant to help the students too much and even to some departments setting limits on how many pages the supervisor is allowed to see before the report is handed in. T. W. Jensen (2018) interviewed 52 experienced supervisors and concluded that although views on the master thesis are diverse, a common theme is independence. Although controversial in some groups, this work is based on the premise that independence is a learning goal -not a prerequisite. Whether at bachelor, master or PhD level, both size, quality and complexity of the project is new to the student and thus requires support regarding both contents and dissemination and providing that should be the main priority of the supervisor.

Most engineering programmes experience a surge in the number of students these years. This pose a challenge for the programmes to provide enough experienced supervisors for final projects. At the same time the programmes admit students with lower grades in order to fill the available seats. The main reason for conducting this research was a suspicion that this combination has lead to a decline in the quality of especially the dissemination part of final projects. We did not investigate whether this assumption is true, but instead went on to investigate how the dissemination skills can be improved.

\section{Analysis}

This qualitative analysis is based on interviews with a cohort of six engineering students. Two students were from the robotics programme and the rest from the electronics programme. One was in the first year of $\mathrm{PhD}$ and the rest were master students. They all had experience from 3-8 group projects and 1-4 individual projects thus giving them a solid basis for the interview.

We hypothesised that engineering students generally begin writing too late into the project to benefit from the writing process. To investigate this we asked them when in 
the project they normally begin to produce written material. They generally reported that they start late, typically a month before deadline which is supported by statements such as: "2-4 weeks before deadline (Martin)", "Close to the end of the project (Rasmus)" and "I normally write after I finish the project. Ideally I spend the last month on writing (Nicolai)". Some also expressed the intention to start early: "I start with an expectation to begin writing early, and usually have some written material quite early in the project. However, the entire remainder of the report usually ends up being written at the very last moment. (Mads)". Finally some expressed that writing naturally happens after the project, supported by for example: "I must be far into the project to get a better insight in what to write. (Mads)". Two students identified writing as a way to remember what was done: "Normally I start writing as soon as I start the project and document things along the way so that I remember what I do (Beck)" and "As soon as I have results [I start writing] so maybe a month or two into the project. When I come back to my work the next day, the next week or the next month I can look back and realise what I was thinking. (Javier)"

We hypothesised that engineering students dislike writing and are mostly interested in the technical contents and not in dissemination. In order to test this we asked the students how they normally feel about writing. Typical answers were: "It can be a hard to get started on the writing but when I am in 'the zone' I actually like it (Nicolai)", "Once I am in it I like it, but getting to that point is not fun (Martin)" and "I somehow like it, although it can be tedious (Javier)". This confirms some aversion against writing, but for very different reasons than expected. They actually enjoy writing but the task can seem insurmountable early in the project. There was also indications that students lack the motivation to write: "It [writing] is something I postpone as long as possible (Martin)". Out of the six students, five of them had this kind of remarks indicating that the problem is consistent across year groups and study programmes. Finally there were also indications that the aversion is selective: "Once I get started it [writing] is sort of OK but I prefer to write about something deeply technical (Rasmus)"

We hypothesised that written work is seen as a secondary activity, something that is required to pass, but otherwise does not contribute to the development of the project. Students were asked how writing normally helps them develop a project and typical answers were: "Not much, we typically brainstorm and then pick the best sounding idea and then later realise that the idea wasn't so good after all (Martin)" and "The report does not really help me, but I usually write a project description and a to-do list to help me stay on track (Nicolai)". All had experienced situations where writing gave them new insights in their projects indicating that the idea is not remote to the students. "Normally I end up writing late in the project period, only to discover too late that I should have done something entirely different (Mads)" and "Writing often gives me ideas about how we should have solved something or things we could have done. It has often been too late to change (Rasmus)". A few students were already aware of the benefits: "It clears my mind to put my thoughts on paper. (Javier)" and "It [writing] helps my thought process. (Beck)"

A big effort is made to support collaboration among students for example by forming study groups or establishing shared lab spaces for project work. However we hypothesised that students mostly collaborate on the technical contents of their projects and not on dissemination. We therefore asked them how much feedback from peers they normally receive on their written work. They consistently answered that this is very rare, supported by statements like: "Sometimes I have received feedback from the supervisor of the project, but very rarely more than that. (Mads)", "If I feel stuck I could ask a friend for feedback, but it is not the most ususal thing. (Javier)", "I only ever got feedback from people in the group or the supervisor (Rasmus)" and "We sometimes discuss the projects, but never in text (Nicolai)". Only one student seemed to tap into this resource reporting that: "I normally ask other students to read my report. Usually at the end of the project, but I occasionally also ask for comments on a section earlier in the project (Beck)". We also asked the opposite question to assess how much they usually review written work for their peers which they rarely do, supported by statements such as: "Very rarely. I have done it maybe three or four times during the entire program [5 years] (Mads)", "A little but typically proof reading the language [as a native speaker] at the end of the project (Beck)", "No. I never see their reports (Nicolai)" and "If I am not involved, never. In group work I try hard to read and give feedback. (Javier)"

We hypothesised that students generally feel that they receive too little feedback. We asked them how much feedback they normally get on their written work and typical answers were: "Too little. It is super constructive so the more the better.(Javier)" and "Not so much. Partly because we generally did not write early enough to get real feedback. (Rasmus)". Only one student thought that feedback was sufficient remarking: "I normally get a lot of feedback, but mostly because I am very aware of using my supervisor. (Beck)"

Based on the above analysis we point out the following problems: 1) Students begin writing too late in the project - because they lack overview of the project in the early stages, because they are focused more on content and implementation than on the written work and because they do not think the writing process benefits the project. 2) Students receive insufficient feedback - because they deliver the material for review too late and because the supervisor spends too little 
time reviewing. 3) Students receive most feedback too late to integrate it - because they deliver the material for review too late. 4) Students do not collaborate about writing - because they deliver the material for review too late. 5) Students are not using the writing process to improve the project - because they begin writing too late to be able to integrate insights and because they do not think the writing process benefits the project.

\section{Model}

It is clear that starting late influences many of the other problems and thus constitutes a root problem. Another root problem is that the supervisor needs more time to review the written work of the students. Solving those two should have great influence on the remaining issues. It is surprising that the students express the desire to begin writing earlier. This is an important resource in changing the behaviour. Although students seem mostly unaware of the benefits of writing, many had experienced gaining new insights from writing which is also a resource. Finally it is interesting that although students are very good at collaborating about the contents and implementation of the project, it is very rare that they collaborate about the written work. This is also an untapped resource. Finally the most important resource to take into consideration is the student's time, since practical development and writing must happen at the same time. It is hard to generalise the distribution of the workload because projects are very different, but near the end the workload seems to be much higher than in the beginning. The most important reason for starting late is that students lack overview both over the project and over the written work. A very good argument for writing is exactly to gain an overview over the project, so initial focus must be on enabling the students to write indicating a need for scaffolding.

The scaffolding concept draws on the model described by Vygotsky (1980) called Zones of Proximal Development (ZPD). The ZPD model describes one zone consisting of tasks that the learner can do without help and another with tasks the learner can't do even with help. What is interesting is the zone between those consisting of tasks the learner can do with assistance since this is identified as the zone in which learning best happens. The purpose of scaffolding is to increase the students' understanding of the task at hand and best prepare them for the challenges ahead. An integral part of scaffolding is that it must be applied in the beginning and then gradually be removed (Beed et al., 1991) thus indicating a spectrum going from early support towards later independence. A well proven way to provide scaffolding for written work is through the use of exemplars where the student is presented with similar work, for example by letting students assess examples from last years exam (Hendry, 2013).
It is well established that feedback has one of the highest effects on student achievements (Hattie \& Timperley, 2007) and that students consistently report to receive too little of it. Feedback given in advance of the task is of high learning value whereas the feedback given with the assessment at the end of the project is of low learning value since the student is unable to change it (Hendry, 2013). This indicates another spectrum where the value offeedback decreases over the project period.

Peer feedback is a way to increase the amount of feedback received by each student at the expense of each student spending some of their time on reviewing written work for their peers. The use of group supervision and peer feedback in dissertation writing was investigated in Dysthe et al. (2006) and they found that students were willing to do so and that the joint activity improved the learning outcome. This is further supported by Baker et al. (2014) stating that "students can benefit from peer support within group supervision without there being adverse effects on their individual out-comes"

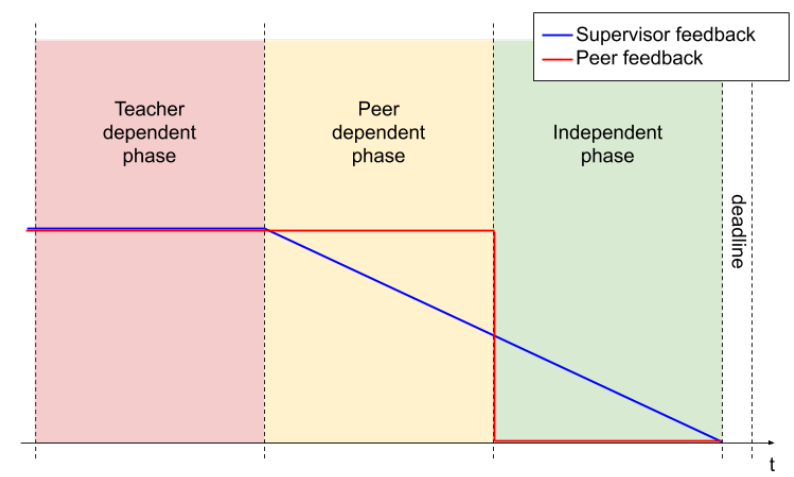

Figure 1. The three phase model showing the distribution of feedback over the project period. The blue line shows the amount of feedback from the supervisor being gradually reduced after the teacher dependent phase. The red line shows the amount of peer feedback as constant during the first two phases where the peer feedback activities run and abruptly ending after that.

Based on the two identified spectra we propose a supervision model in three phases (figure 1). In the teacher dependent phase the supervisor must take on a leading role. The supervision meetings should consist of lectures priming the students for the upcoming challenges. The students should work with given assignments and the supervisor must give thorough, process-level feedback on them. Apart from the written assignments the students should focus on the project and on obtaining the knowledge necessary in the practical part of the project. In the peer dependent phase the supervisor should continue to have a structuring role, but the contents of the assignments should be chosen individually by the students. The feedback should come mostly from peers while the supervisor should monitor the process and mostly give 
feedback on the scientific contents of the work. In the independent phase the student is left to finish the practical project and write the dissertation. The supervisor's role should be as a partner in the project (Dysthe et al., 2006) discussing science, facilitate the practical work and helping to mediate concrete problems. The peer feedback should be structured in assignments. In each assignment the student must produce material for the dissertation. This is important to ensure alignment between the assignments and the end goal which help keep students motivated. During the teacher dependent phase the assignments are given by the supervisor and in the peer dependent phase they consist of excerpts of the dissertation selected by the student and thus directing the feedback to the needs of the student. The purpose of the given assignments is to scaffold the project design and to help the student establish an overview of the project.

In order to implement this model it is necessary to free up some of the supervisor's time to make up for the extra time spent on giving feedback. We propose to do so by forming a supervision group consisting of all the students supervised by the same researcher. Group supervision can reduce the time spent on supervision compared to having individual supervision meetings (Ottosen et al., 2014). Instead of explaining the same procedures, concepts, practicalities and methods multiple times, they can be explained to all students at once and similar questions can also be answered just once. It is required that the projects share a common subject and there are limits on how many students can be in a group (2-7 according to H. N. Jensen (2015)). The group should meet at regular intervals, most often early in the project and rarer towards the end. The didactic purpose of group supervision is to provide structure, especially in the beginning of the project and to provide a framework for the scaffolding initiatives.

The scaffolding initiatives should be adapted to the group based on background, experience etc. We propose three categories to consider: Tools, project design and methods. The purpose of introducing tools is to enable students to best gain from this supervision strategy and to motivate them to spend valuable time on joint activities. It could be subjects such as presenting the strategy, how to give feedback, rubrics or elearning tools. The project design activities should help the student get an overview of their project, to focus the scope of the project and to see the advantage of writing to support thinking. This could for example be giving an elevator pitch or how to write a good abstract. Finally the purpose of the methods activities is to prepare the students for the writing process and give collective information to relief the supervisor of repeating it. That would be topics like literature review, requirements specification, practicalities or formal requirements. The scaffolding initiatives should reside in the teacher dependent phase.
Activity

We planned and conducted an activity based on the presented strategy. The activity ran in the fall semester 2018 at University of Southern Denmark and concerned the cohort interviewed for the analysis. We formed a supervision group consisting of the six engineering students and a supervisor. One student was writing a paper, two students did a masters project as a group and the remaining four were doing individual master projects. All projects concerned aspects the supervisor's research in embedded electronics. The group met every other week for a total of nine meetings. Each meeting was scheduled to last two hours, but rarely lasted more than one.

The students had homework to do every time producing written material for their project. The material was handed in three days before the meeting via the peer review tool (Peergrade, 2018) to allow the other students to give feedback on it. The feedback was structured to follow a rubric discussed the week before and two randomly selected students gave feedback on each hand in. The teacher also gave written feedback in peergrade.io but for all hand ins. At each meeting there was a project round where the students stated their progress, problems encountered etc. This was also an opportunity for the students to ask questions. The strategy for the supervisor was to further the discussions as opposed to just giving answers. It was possible for the students to schedule an individual meeting, with the supervisor, which a few of them did for deeper scientific discussions or private matters.

The scaffolding initiatives took up the first three lessons (see table 1 for an overview). The focus of the first lecture was to motivate the supervision strategy and kick-start the activity. The following assignment was to write a somewhat fictional abstract in advance of their final project in order to focus the projects and to provide overview. The lecture consisted of a short presentation about using rubrics and then an exercise where the students step-by-step constructed a rubric for The good abstract.

The focus of the second meeting was how to give good feedback and it consisted of presentation introducing the feedback model from Hattie \& Timperley (2007) followed by a discussion with the students about their experiences with good and bad feedback. The tool used for peer review (peergrade.io) was introduced. The review functionality of this tool allows the supervisor to set up a custom rubric so the feedback directly followed the rubric constructed in the first meeting. Finally the abstracts were reviewed in class. Each contribution was reviewed by two peers and the supervisor and feedback had to be submitted before they could see the other reviews. The second assignment was to rewrite the abstract based on the received feedback and was due three days before the following meeting. Reviews were then due on the 


\begin{tabular}{|l|l|l|l|l|}
\hline Meeting & Date & Lecture & Rubric & Assignment \\
\hline 1 & $14 / 9$ & Peergrade, rubrics & The good Abstract & Write abstract \\
\hline 2 & $28 / 9$ & Good feedback & The good abstract & Rewrite abstract. \\
\hline 3 & $12 / 10$ & Literature search & The good literature review & Write literature review \\
\hline 4 & $26 / 10$ & None & The good Requirements specification. & Write requirements specification \\
\hline 5 & $9 / 11$ & None & None & Write chapter \\
\hline 6 & $23 / 11$ & None & None & None \\
\hline 7 & $7 / 12$ & None & None & None \\
\hline 8 & $21 / 12$ & None & None & None \\
\hline 9 & $11 / 1$ & Presentations & None & None \\
\hline
\end{tabular}

Table 1

The contents of the meetings. Red marks the teacher dependent phase, yellow the peer dependent phase and green the independent phase.

day of the meeting to allow students to read them in preparation. The third lecture was about the literature review. The presentation introduced the purpose of the literature review, tools for literature search and formal requirements to citations. The students were given a rubric for The good literature review and the following assignment was to write one and give feedback on two. The supervisor gave feedback on all contributions. The remaining meetings did not have lectures and in the following two assignments students decided what to hand in. They were encouraged to focus on the requirements specification first as this is an essential but challenging part of most projects. Again each student reviewed two contributions while the supervisor reviewed all of them. After the assignments the meetings only served as supervision meetings. The last meeting was held after handing in the projects and concerned the defence presentations. After each presentation both peers and supervisor gave feedback.

The students were interviewed after the activity and a qualitative analysis of the interviews were performed.

\section{Results}

We hypothesised that increasing scaffolding in the beginning of the project via assignments would make it easier for the students to get started early. All students began writing early and there were indications that they began earlier than normal supported by statements such as: "This time I began writing almost at the beginning. I would normally have waited another month or so (Javier)", "I started earlier than I usually do. (Nicolai)" and "It was a lot different this time. The actual content of the report was written almost side by side with the development of the project. (Mads)". There were also indications that this was an effect of scaffolding: "I found that the general structure of the report, as well as the content of project was easier to grasp early in the project period. (Mads)".

We hypothesised that getting started early would increase the value of the writing process. All students noticed advantages of the writing process. Some statements indicated increased reflection: "We though more thoroughly about the written part of the project and writing the abstract helped us define the direction of the project in the beginning instead of in the end. (Martin)", "I have been forced to think more about the project than I usually do. In making the literature review I found that some work I expected to do had already been done. (Rasmus)" and "Writing the abstract forced me to think through the entire project in advance. That is something I will do again to gain an early overview of a project (Rasmus)". Some expressed that it improved their overview of the project in statements like: "It helped a lot to write the abstract. It helped to summarize and clear things (Javier)" and "The abstract exercise was good and helped give me overview. (Nicolai)". Some also noticed a reduced risk for mistakes articulated in sentences such as: "We reflected more in the writing process which made us realise mistakes earlier. It saved us a lot of development time and this time there were no big mistakes realised at the end of the project. (Martin)", "I properly learned to not make some of the usual mistakes I do, when writing a report. (Mads)" and "We also began documenting the implementations in advance for example describing the idea or the setup which also made us realise problems early. (Martin)". Finally one student expressed a change of focus: "Normally I write more about the implementation, but this time my focus was on other things like abstract and literature review (Beck)"

We hypothesised that receiving feedback early in the project would increase its effect. All students agreed that they received more feedback than usual demontrated in statements like: "I had much more feedback (Rasmus)", "I received a lot more feedback this time and it made me much more focused. (Javier)" and "I got much more, and way better feedback this time. (Mads)". Some statements also indicated increased effect: "I guess I was more willing to change my style because I got the feedback earlier. The less you have to go back and scrap the hole thing, the more positive the experience (Beck)" 
and "It made me realise some things I could do different. In that way it was helpful. Especially the feedback from [supervisor] and [named peer] was super useful because it made me focus the project. (Javier)"

We hypothesised that reviewing the work of peers would inspire development in ones own writing skills. The students were generally happy to review each others work and several statements indicate that it inspired their own work for example: "I guess it helped me to read the others' abstracts. Some of them made very obvious mistakes that I later found in my own work. Realising what works and not also helped me. I saw both good and bad things that influenced my own project (Javier)", "Reviewing other people's work has shown me alternative ways to write. I also really enjoyed reading about the projects.(Rasmus)" and "It was inspiring. Seeing their reports made me 'copy' the structure. It is nice to see how others did it. Also I was a bit uneasy in the situation and seeing what others did made me more confident and assured me that I was not completely off. (Nicolai)".

We hypothesised that students would be more critical towards feedback from their peers than from the supervisor. There were such indications, for example: "Relating to feedback from people on my own level makes me more critical about the feedback (Rasmus)" and "I would say that generally the quality of feedback from your peers is low and I would also grade my own feedback as low quality because we don't have the time and have to focus on our own project. However I think that because we had different specialities we can ask some naiive questions which allow you to explain vague parts in a better way. (Beck)". There were also indications of the opposite like: "It is nice to know if the text is comprehensive. I made many changes based on the [peer] feedback (Nicolai)", "Getting three different sets of eyes on it every time worked really well. Quality was higher than expected.(Rasmus)" and "It is nice get an outside view not just on the contents but also on the writing technique. (Nicolai)". Some respondents also reflected on the reason in statements such as: "There is a quality difference, mostly because peers tend to be more polite and supportive. It can be motivating but it is more helpful to make me bleed a little bit (Javier)" and "What really made the difference I think, was that we gave feedback, based on questions discussed beforehand [rubric]. Having a tool and/or the questions, made the feedback much more useful, and not as 'fluffy' as without the tools. (Mads)"

With individual supervision the supervisor would normally meet approximately 45 minutes every other week with individual students and one hour with groups. With a total of ten meetings during the semester that would amount to roughly 50 hours with this cohort. The meetings in this activity took in total approximately 15 hours and reviewing the 25 assignments another 15 hours, leaving around 20 hours to prepare lectures and orchestrate everything. This indicates that most supervisors should be able to apply the strategy without spending more time than unusual on supervision. We even argue that with training it is possible save time or to supervise more students.

\section{Conclusion}

In this work we investigated the writing process in the final projects of engineering students. We found that students begin writing too late and receive insufficient feedback. Based on those findings we proposed a model for the distribution of feedback during the project and revised a supervision strategy to help the supervisor mediate said challenges. In the following experiment we showed that scaffolding can make students write from the beginning of the project and that starting early can increase the value of the writing process. We further showed that giving feedback early in the project increased the value of feedback and that peer review and group supervision can inspire development in writing skills and increase collaboration among students. Finally we showed that this improvement can be implemented without spending more time on supervision.

\section{References}

Baker, M.-J., Cluett, E., Ireland, L., Reading, S., \& Rourke, S. (2014). Supervising undergraduate research: A collective approach utilising groupwork and peer support. Nurse Education Today, 34(4), 637-642.

Beed, P. L., Hawkins, E. M., \& Roller, C. M. (1991). Moving learners toward independence: The power of scaffolded instruction. The Reading Teacher, 44(9), 648-655.

Dysthe, O., Samara, A., \& Westrheim, K. (2006). Multivoiced supervision of masterâĂŹs students: a case study of alternative supervision practices in higher education. Studies in Higher education, 31(03), 299-318.

Hattie, J., \& Timperley, H. (2007). The power of feedback. Review of educational research, 77(1), 81-112.

Hendry, G. (2013). Integrating feedback with classroom teaching. Reconceptualising Feedback in Higher Education: Developing Dialogue with Students, Routledge, 133-141.

Jensen, H. N. (2015). Opgave- og skrivevejledning i klynger. Samfundslitteratur.

Jensen, T. W. (2018). Det danske universitetsspeciale. topografi, tekster og tendenser. ÃĚrhus Universitetsforlag.

Ottosen, L., Goltermann, P., \& Jensen, P. (2014, 06). Organization of bsc and msc projects in project families..

Peergrade. (2018), peergrade.io. https://www. peergrade.io/. (Accessed: 2019-04-26) 
Vygotsky, L. S. (1980). Mind in society: The development of 